\title{
Ground Validation of the Third Generation JPL Electronic Nose
}

\author{
M. A. Ryan, A. V. Shevade, A. K. Kisor, \\ K. S. Manatt, M. L. Homer, L. M. Lara and H. Zhou \\ Jet Propulsion Laboratory, California Institute of Technology, Pasadena CA 91109
}

Copyright (C) 2008 SAE International

\begin{abstract}
The Third Generation ENose is an air quality monitor designed to operate in the environment of the US Lab on the International Space Station. It detects a selected group of analytes at target concentrations in the ppm regime at an environmental temperature range of 18 $30{ }^{\circ} \mathrm{C}$, relative humidity from $25-75 \%$ and pressure from 530 to 760 torr. The abilities of the device to detect ten analytes, to reject confounders as "unknown" and to deconvolute mixtures of two analytes under varying environmental conditions has been tested extensively in the laboratory. Results of ground testing showed an overall success rate for detection, identification and quantification of analytes of $87 \%$ under nominal temperature and humidity conditions and $83 \%$ over all conditions.
\end{abstract}

\section{INTRODUCTION}

The JPL Electronic Nose [1-5] is an event monitor designed and built for near real time air quality monitoring in crew habitat aboard the space shuttle/space station. This is an array-based sensing system which is designed to run continuously and to monitor for the presence of selected chemical species in the air at parts-per-million (ppm) to parts-per-billion (ppb) concentrations.

There have been three phases of development of the JPL Electronic Nose. In the first phase, a device capable of detecting, analyzing and quantifying ten analytes at the 1-hour Spacecraft Maximum Allowable Concentration (SMAC) was developed. This device was tested successfully in 1998 on Space Shuttle flight STS95 [4]. In the second phase, the ENose was miniaturized and the capabilities were significantly expanded to include 21 analytes and detection at varying humidity and temperature. The Second Generation ENose was tested extensively on the ground and was demonstrated to be able to detect, identify and quantify the 21 analytes at or below their 24-hour SMACs [6]. In preparation for an upcoming, six-month technology demonstration aboard the International Space Station (ISS) in 2008-09, the JPL ENose team is developing a Third Generation ENose which is designed to monitor spacecraft cabin air quality in near real-time.

Development of the Third Generation JPL ENose has required two major areas of development. One area is the design and fabrication of an interface unit which will allow the ENose to be operated through the EXPRESS Rack (EXpedite The PRocessing Of Experiments To Space Station) on the ISS for a six-month technology demonstration experiment. The second area of development includes the sensing platform and the data analysis software. Using the Second Generation ENose as a base, the sensing materials, sensor substrate, and data analysis routines are being expanded in order to include the ability to detect additional inorganic species, mercury and sulfur dioxide, and to provide quasi-real time data analysis. The design and development of the $3^{\text {rd }}$ Generation ENose has been discussed in detail elsewhere $[7,8]$.

This paper will focus on extensive laboratory testing of the capabilities of the $3^{\text {rd }}$ Generation Electronic Nose (ENose) under a variety of environmental conditions.

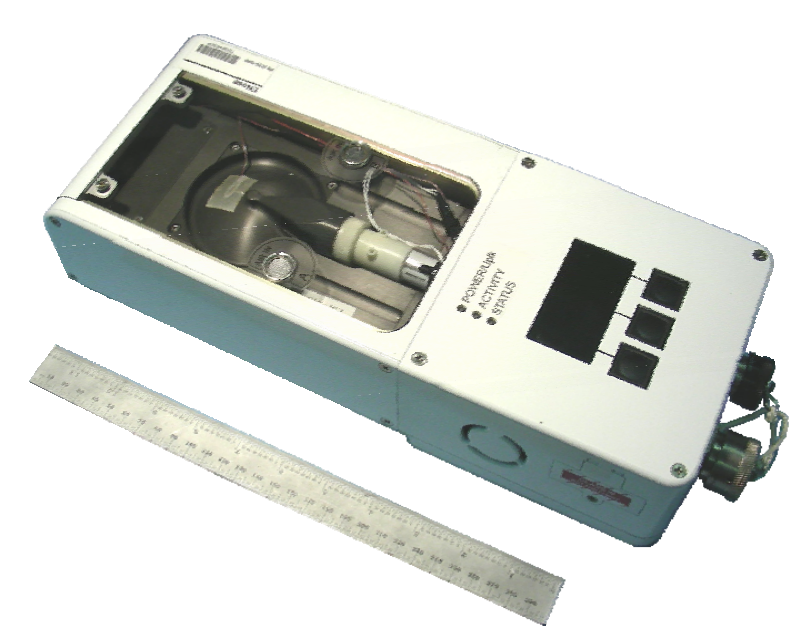

Figure 1: The Third Generation ENose. The Sensor Unit is enclosed in the Interface Unit, which will be connected to the ISS EXPRESS Rack 
requirement for this program; however, formaldehyde was treated as a Tier 2 analyte for ease of testing.

\section{THE THIRD GENERATION JPL ENOSE}

The ENose was tested for response and ability to identify and quantify eleven chemical species, shown in Table1. A quantification is considered to be correct if the concentration value reported by the ENose data analysis software is $+/-50 \%$ of the independently measured concentration of the species. The error range of $+/-50 \%$ in quantification is based on the approximate range with which the Spacecraft Maximum Concentrations (SMACs) are set; toxicities are not well known for most chemical species, and SMACs are set very conservatively.

Success rate in analyte identification and quantification is the number of correctly identified and quantified deliveries of analyte, minus the number of false negatives and false positives, divided by the number of deliveries of analyte. A false negative is failure to detect the delivery and presence of a targeted chemical species. A false positive is a report of the presence of a chemical species when it was not present. Misidentification of a targeted species, for example identifying propanol as methanol, or identifying a confounder as a targeted species, is considered to be a false positive.

Table 1: Analyte List and Target Detection Concentration; $\mathrm{mg} / \mathrm{m}^{3}$ is a pressure independent unit; ppm is for $1 \mathrm{~atm}$.

\begin{tabular}{|l|l|c|c|}
\hline & ANALYTE & $\begin{array}{c}\text { QUANT. } \\
\text { TARGET } \\
\text { (mg/m } \mathbf{3})\end{array}$ & $\begin{array}{c}\text { QUANT. } \\
\text { TARGET } \\
\text { (ppm) }\end{array}$ \\
\hline TIER 1 & Ammonia & 3.5 & 5.0 \\
\hline & Mercury & 0.080 & 0.010 \\
\hline & Sulfur Dioxide & 3.0 & 1.0 \\
\hline TIER 2 & Acetone & 500 & 200 \\
\hline & Dichloromethane & 35 & 10 \\
\hline & Ethanol & 940 & 500 \\
\hline & Freon 218 & 150 & 20 \\
\hline & Methanol & 13 & 10 \\
\hline & 2-Propanol & 240 & 100 \\
\hline & Toluene & 60 & 16 \\
\hline TIER 3 & Formaldehyde & 0.12 & 0.10 \\
\hline
\end{tabular}

The chemical species in Table 1 are divided into three tiers, based on the importance to NASA Habitability and Environmental Factors Office in detecting these species. Formaldehyde was classified as Tier 3 because its identification and quantification was a goal, not a

\section{ENVIRONMENTAL CONDITIONS}

The environmental conditions under which testing was done were defined according to conditions which can be expected in the US Lab on the ISS. Background air composition was based on allowed ISS atmospheric concentrations of water, carbon dioxide and methane. Relative humidity $(\mathrm{RH})$ may vary from $25-75 \%$ at temperatures of $18^{\circ} \mathrm{C}-30^{\circ} \mathrm{C}, \mathrm{CO}_{2}$ concentration may be as much as $\sim 15 \mathrm{~mm} \mathrm{Hg}$ partial pressure and $\mathrm{CH}_{4}$ may be several hundred ppm). Atmospheric pressure in the ISS may vary from 538 - 760 torr (10.4 to 14.7 psi) and may rise for brief periods (minutes) as high as 830 torr (16 psi).

Temperature may vary over the range $18-30^{\circ} \mathrm{C}$ (66 to $86{ }^{\circ} \mathrm{F}$ ). Nominal conditions are 760 torr, temperature 21$23^{\circ} \mathrm{C}$ and relative humidity $30-40 \%$. Testing was done under all conditions, but not all concentrations of all analytes were tested under all conditions. For repeatability in testing, water content was controlled as $\mathrm{ppm}$ water rather than as relative humidity. Nominal conditions on orbit in ISS correspond approximately to $21-22^{\circ} \mathrm{C}, 10,000 \mathrm{ppm}$ water, and atmospheric pressure.

\section{TRAINING SETS}

As the ENose is an array-based chemical sensor device, before it can be used as an air quality monitor, training sets must be acquired. Based on the training sets, the patterns of array response to targeted analytes under specified conditions are included in the data analysis algorithm.

Data from the ENose are recorded for each individual sensor as resistance versus time. Because the ENose is designed to function as an event monitor, the data are analyzed as change in resistance vs. time. Individual sensor resistances are recorded simultaneously, with a point being taken every twenty seconds. While it would be possible to take data more or less frequently than three times a minute, this data rate has been established as an optimum rate to show fairly rapid changes in the environment without overwhelming computer memory with data. Our data analysis approach defines an "event' as a change in the composition of the environment which lasts longer than ten minutes, or thirty points at the standard data rate, in part because events of duration shorter than ten minutes cannot practically be addressed or mitigated using either breathing apparatus or clean-up techniques. The data analysis algorithm needs about ten points $(\sim$ three 
minutes) to establish that resistance has changed significantly. Based on the data rate and needs of the data analysis algorithm, training sets are established using vapor deliveries, or events, of 30-45 minutes duration.

The data analysis algorithm is a Levenberg-Marquart non-linear least squares fitting approach to deconvolution of change in resistance across the sensing array into identification and quantification of the analyte causing response in the sensors. The analysis approach has been discussed in detail previously [9].

Training sets were established for the eleven analytes in Table 1. The environmental conditions for the training sets vary only in water content. Because there is temperature control in the sensing chamber in the ENose, the environmental temperature does not influence the temperature at which analytes are detected, identified and quantified. Detection temperature is held at $25-27^{\circ} \mathrm{C}$ for all training sets. Detection temperature rises above $27^{\circ} \mathrm{C}$ only when environmental temperature approaches $30^{\circ} \mathrm{C}$, the maximum temperature for ENose operation, in which case detection temperature will be $27-28^{\circ} \mathrm{C}$. The relative humidity of the environment will be altered if the temperature of the sensing chamber is different from the temperature of the environment, so for training sets, the humidity is regulated as ppm water. Training sets were made in a background of filtered house air with water concentrations of $5000,10,000,15,0000$ and 20,000 $\mathrm{ppm}$. These concentrations correspond roughly to $20 \%$, $40 \%, 60 \%$ and $80 \%$ relative humidity at $21^{\circ} \mathrm{C}$, and cover the specified range of humidities for the specified range of temperatures.

Initial training sets where pressure was varied showed that the sensor resistance changes with respect to the presence of analyte were not dependent on environmental pressure, so a complete set of varied pressure training sets was not made.

In designing training sets, the range of analyte concentration to which sensors are exposed is set at $1 / 3$ to 3 times the target concentration. This range is divided into 10-12 concentrations, and the sensor array exposed to those concentrations at each water content. A total of 1599 different analyte exposures were made to establish the training sets; 325 for Tier 1 compounds and 1274 for Tiers $2 \& 3$. The exposures were divided approximately equally among four humidity levels, although there was a larger number at the two lowest humidities in both sets, Tier 1 and Tiers $2 \& 3$. Formaldehyde, the one Tier 3 compound, had the fewest exposures, as it was a goal rather than a requirement in this program.

Training sets give insight into the conditions under which the ENose operates best, which conditions cause difficulties in identification and quantification, and allow calculation of performance as accuracy of identification and quantification, number of false negatives and number of false positives using a large number of trials.
Training sets can be used to judge the accuracy of the identification and quantification algorithm even though they are used to establish the coefficients. Accuracy of the algorithm has been computed using half the data to establish the algorithm and coefficients and the other half to test the application, and using all the data for both functions. The statistical difference in results is insignificant. In the success rates for identification and quantification shown below, all the data are used for both functions.

\section{SUCCESS RATES}

Tables 2 and 3 summarize the identification and quantification accuracy results based on training sets. In these data, success in detection signifies that the analyte was detected, identified correctly, and quantified within $+/-50 \%$ of the measured delivered concentration of analyte. An "event" is defined as a change in environment caused by the presence of a targeted species. A false positive is detection of an "event," either where there was no event, or mis-identification of an event (e.g. identification of toluene as methanol.) A false negative is failure to identify that an event has happened, without respect to identification or quantification.

As can be seen from both Tables 2 and 3, accuracy in identification of analytes is best at nominal humidity conditions, approximately 10,000 ppm water (30-40\% $\mathrm{RH})$. The overall success rate for identification and quantification is better when the water content of the air is not at its highest; for Tier 1 species, the overall success rate at nominal temperature and humidity is $93 \%$, and for Tier 2 the overall success rate at nominal conditions is $85 \%$.

At conditions of $50-60 \%$ relative humidity with environmental temperature above $21-22^{\circ} \mathrm{C}$, the increased water absorbed by polymer based sensors lowers the sensor responses to other vapors. In addition, high water content in polymer based sensors can result in dissolution of some Tier 2 compounds, particularly oxygen-containing compounds, which will result in a different type of capture of analyte molecules in the sensing film. At high humidity, overall success rate for Tier 1 species falls to $82 \%$ and to $74 \%$ for Tier 2 species. Sensors for mercury are inorganic, and so are not significantly affected by humidity; the fall in success with humidity for Tier 1 species is cause by a slight fall in success with ammonia and a significant fall in success for $\mathrm{SO}_{2}$. With Tier 1 species, lower, but not zero, humidity tends to be better for sensing, especially with $\mathrm{SO}_{2}$, which reacts with water to form sulfuric acid. Sensor response to ammonia falls off with humidity as it does for the organic species in Tier 2; it is the same polymer sensors which are used to detect and quantify organic compounds that are used in sensing ammonia. 
For Tier 2 compounds, lower humidity, 5000 ppm water, and slightly higher than nominal humidity, 15,000 ppm water, have similar overall accuracy, success rates of $80 \%$ and $79 \%$, respectively. The overall accuracy at the high end of humidity conditions, $20,000 \mathrm{ppm}$, is significantly lower that at the lower humidities for Tier 2 species, as it is for Tier 1.

The Tier 3 species, formaldehyde, is detected well at nominal conditions, but poorly at high humidities.
Because the concentration of formaldehyde is very low, and because it is a small molecule, response to this compound is masked by response to water at high humidity. Although the ENose program has worked to develop approaches to deconvolute response to an analyte masked by high humidity, in the case of formaldehyde, which has a very small signal in polymer sensors, the sensor response cannot be separated.

Table 2: Analyte ID success rates for Tier 1 chemical species, based on training set data

\begin{tabular}{|l|r|r|r|r|}
\hline $\begin{array}{l}\text { Analyte at } 25^{\circ} \mathrm{C}, 5000 \mathrm{ppm} \\
\mathrm{H}_{2} \mathrm{O}-\mathbf{1 6 \%} \mathrm{RH}\end{array}$ & Correct & False Pos & False Neg & $\begin{array}{c}\text { Number } \\
\text { of events }\end{array}$ \\
\hline Ammonia (2-25) & 0.90 & 0.17 & 0.00 & 46 \\
\hline Mercury (.003-.03) & 0.95 & 0.04 & 0.01 & 24 \\
\hline Sulfur Dioxide & 0.94 & 0.05 & 0.01 & 24 \\
\hline Average, Tier 1 & $\mathbf{0 . 9 3}$ & $\mathbf{0 . 0 1}$ & $\mathbf{0 . 0 0}$ & $\mathbf{9 4}$ \\
\hline
\end{tabular}

\begin{tabular}{|l|r|r|r|r|}
\hline $\begin{array}{l}\text { Analyte at } 25^{\circ} \mathrm{C}, 10000 \mathrm{ppm} \\
\mathrm{H}_{2} \mathrm{O}-32 \% \mathrm{RH}\end{array}$ & Correct & False Pos & False Neg & $\begin{array}{c}\text { Number } \\
\text { of events }\end{array}$ \\
\hline Ammonia (2-25) & 0.93 & 0.07 & 0.00 & 42 \\
\hline Mercury (.003-.03) & 0.95 & 0.04 & 0.01 & 24 \\
\hline Sulfur Dioxide & 0.92 & 0.07 & 0.01 & 24 \\
\hline Average, Tier 1 & $\mathbf{0 . 9 3}$ & $\mathbf{0 . 0 2}$ & $\mathbf{0 . 0 0}$ & $\mathbf{9 0}$ \\
\hline
\end{tabular}

\begin{tabular}{|l|r|r|r|r|}
\hline $\begin{array}{l}\text { Analyte at } 25^{\circ} \mathrm{C}, 15000 \mathrm{ppm} \\
\mathrm{H}_{2} \mathrm{O}-\mathbf{4 8} \% \mathrm{RH}\end{array}$ & Correct & False Pos & False Neg & $\begin{array}{c}\text { Number } \\
\text { of events }\end{array}$ \\
\hline Ammonia (2-25) & 0.87 & 0.13 & 0.00 & 60 \\
\hline Mercury (.003-.03) & 0.93 & 0.07 & 0.00 & 15 \\
\hline Sulfur Dioxide & 0.77 & 0.22 & 0.01 & 15 \\
\hline Average, Tier 1 & $\mathbf{0 . 8 6}$ & $\mathbf{0 . 0 5}$ & $\mathbf{0 . 0 0}$ & $\mathbf{9 0}$ \\
\hline
\end{tabular}

\begin{tabular}{|l|r|r|r|r|}
\hline $\begin{array}{l}\text { Analyte at } 25^{\circ} \mathrm{C}, 20000 \\
\text { ppm } \mathrm{H}_{2} \mathrm{O}-\mathbf{6 4 \%} \mathrm{RH}\end{array}$ & Correct & False Pos & False Neg & $\begin{array}{c}\text { Number } \\
\text { of events }\end{array}$ \\
\hline Ammonia (2-25) & 0.81 & 0.19 & 0.00 & 31 \\
\hline Mercury (.003-.03) & 0.92 & 0.08 & 0.00 & 10 \\
\hline Sulfur Dioxide & 0.73 & 0.25 & 0.02 & 10 \\
\hline Average, Tier 1 & $\mathbf{0 . 8 2}$ & $\mathbf{0 . 0 4}$ & $\mathbf{0 . 0 0}$ & $\mathbf{5 1}$ \\
\hline
\end{tabular}

\begin{tabular}{|c|r|r|r|r|}
\hline & Correct & False Pos & False Neg & $\begin{array}{r}\text { Number } \\
\text { of events }\end{array}$ \\
\hline $\begin{array}{c}\text { Average, Tier1 over all } \\
\text { conditions }\end{array}$ & 0.89 & 0.03 & 0.00 & 325 \\
\hline
\end{tabular}


Table 3: Analyte ID success rates for Tier 2 \& 3 chemical species, based on training set data

\begin{tabular}{|c|c|c|c|c|}
\hline $\begin{array}{l}\text { Analyte at } 25^{\circ} \mathrm{C}, 5000 \text { ppm } \\
\mathrm{H}_{2} \mathrm{O}-16 \% \mathrm{RH}\end{array}$ & Correct & False Pos & False Neg & $\begin{array}{l}\text { Number } \\
\text { of events }\end{array}$ \\
\hline Acetone (91 - 1000) & 0.90 & 0.10 & 0.00 & 30 \\
\hline DichloroMethane (3 - 45) & 0.63 & 0.37 & 0.00 & 31 \\
\hline Ethanol (167 - 2001) & 0.90 & 0.10 & 0.00 & 30 \\
\hline Freon $218(6-100)$ & 0.70 & 0.29 & 0.01 & 61 \\
\hline Methanol $(3-50)$ & 0.83 & 0.16 & 0.01 & 30 \\
\hline 2-Propanol (30 - 500) & 0.74 & 0.26 & 0.00 & 61 \\
\hline Toluene $(7-76)$ & 0.97 & 0.03 & 0.00 & 30 \\
\hline Formaldehyde (0.03 - 0.3) & 0.72 & 0.27 & 0.01 & 27 \\
\hline Average, Tiers $2 \& 3$ & 0.80 & 0.20 & 0.00 & 300 \\
\hline
\end{tabular}

\begin{tabular}{|l|r|r|r|r|}
\hline $\begin{array}{l}\text { Analyte at } \mathbf{2 5}{ }^{\circ} \mathbf{C}, \mathbf{1 0 0 0 0} \mathbf{~ p p m} \\
\mathbf{H}_{2} \mathbf{O}-\mathbf{3 2 \%} \mathbf{R H}\end{array}$ & Correct & False Pos & False Neg & $\begin{array}{c}\text { Number } \\
\text { of events }\end{array}$ \\
\hline Acetone (91 - 1000) & 0.91 & 0.09 & 0.00 & 43 \\
\hline DichloroMethane (3- 45) & 0.75 & 0.25 & 0.00 & 60 \\
\hline Ethanol $(167-2001)$ & 0.88 & 0.12 & 0.00 & 32 \\
\hline Freon 218 (6-100) & 0.67 & 0.33 & 0.00 & 73 \\
\hline Methanol (3- 50) & 0.87 & 0.13 & 0.00 & 30 \\
\hline 2-Propanol (30-500) & 0.88 & 0.12 & 0.00 & 74 \\
\hline Toluene (7- 76) & 0.93 & 0.07 & 0.00 & 30 \\
\hline Formaldehyde (0.01 - v0) & 0.93 & 0.06 & 0.01 & 27 \\
\hline Average, Tiers 2\&3 & $\mathbf{0 . 8 5}$ & $\mathbf{0 . 1 5}$ & $\mathbf{0 . 0 0}$ & $\mathbf{3 6 9}$ \\
\hline
\end{tabular}

\begin{tabular}{|l|r|r|r|r|}
\hline $\begin{array}{l}\text { Analyte at } \mathbf{2 5}^{\circ} \mathbf{C}, \mathbf{1 5 0 0 0} \mathbf{~ p p m} \\
\mathrm{H}_{2} \mathbf{O}-\mathbf{4 8 \%} \mathrm{RH}\end{array}$ & Correct & False Pos & False Neg & $\begin{array}{c}\text { Number } \\
\text { of events }\end{array}$ \\
\hline Acetone & 0.94 & 0.06 & 0.00 & 31 \\
\hline DichloroMethane & 0.77 & 0.23 & 0.00 & 31 \\
\hline Ethanol & 0.90 & 0.10 & 0.00 & 31 \\
\hline Freon 218 & 0.79 & 0.19 & 0.02 & 62 \\
\hline Methanol & 0.68 & 0.32 & 0.00 & 31 \\
\hline 2-Propanol & 0.90 & 0.10 & 0.00 & 31 \\
\hline Toluene & 0.97 & 0.03 & 0.00 & 31 \\
\hline Formaldehyde & 0.35 & 0.65 & 0.00 & 15 \\
\hline Average, Tiers 2\&3 & $\mathbf{0 . 7 9}$ & $\mathbf{0 . 2 1}$ & $\mathbf{0 . 0 0}$ & $\mathbf{2 6 3}$ \\
\hline
\end{tabular}

\begin{tabular}{|l|r|r|r|r|}
\hline $\begin{array}{l}\text { Analyte at } \mathbf{2 5}^{\circ} \mathbf{C}, \mathbf{2 0 0 0 0} \\
\text { ppm } \mathrm{H}_{\mathbf{2}} \mathbf{O}-\mathbf{6 4 \%} \mathbf{R H}\end{array}$ & Correct & False Pos & False Neg & $\begin{array}{c}\text { Number } \\
\text { of events }\end{array}$ \\
\hline Acetone & 0.90 & 0.10 & 0.00 & 31 \\
\hline DichloroMethane & 0.63 & 0.37 & 0.00 & 62 \\
\hline Ethanol & 0.90 & 0.10 & 0.00 & 31 \\
\hline Freon218 & 0.42 & 0.57 & 0.01 & 62 \\
\hline Methanol & 0.87 & 0.11 & 0.02 & 62 \\
\hline 2-Propanol & 0.87 & 0.13 & 0.00 & 33 \\
\hline Toluene & 0.90 & 0.10 & 0.00 & 31 \\
\hline Formaldehyde & 0.46 & 0.53 & 0.01 & 30 \\
\hline Average, Tiers 2\&3 & $\mathbf{0 . 7 4}$ & $\mathbf{0 . 2 5}$ & $\mathbf{0 . 0 1}$ & $\mathbf{3 4 2}$ \\
\hline
\end{tabular}

\begin{tabular}{|c|r|r|r|r|}
\hline & Correct & False Pos & False Neg & $\begin{array}{c}\text { Number of } \\
\text { events }\end{array}$ \\
\hline $\begin{array}{c}\text { Average, Tiers 2\&3 } \\
\text { over all conditions }\end{array}$ & 0.80 & 0.20 & 0.00 & 1274 \\
\hline
\end{tabular}


The reasons for lower success rates at lower humidity with Tier 2 (organic) compounds are not clear. A model of sensor-analyte interaction developed under the JPL ENose program has shown that the interaction energy of an analyte with the sensor matrix is decreased as water content in the sensor increases; it might therefore be expected that air with lower humidity, 5000 ppm water or $\mathrm{RH}$ about $20 \%$, would result in better success rates than air with nominal humidity (about 40\% RH) [10, 11]. However, the data in Table 4 indicate that this is not the case. It is possible that this phenomenon comes from the methods used to select the sensor set. Data used in selecting the polymer materials from which to make the sensors were taken at 10000 ppm water in air, and so the sensor set has been optimized for this humidity level. Future applications, where conditions might vary more than typical conditions on ISS, will have to take that variation into account in optimizing the sensor set.

The model of sensor-analyte interaction also shows that the binding energy of analyte in a polymer sensor will decrease with rising temperature. Even a modest rise in temperature is sufficient to prevent weak bonding such as hydrogen bonding between analyte and sensor. In fact, it is in part because of this ability of modest temperature increase to prevent weak bonding that the polymer sensors in the ENose are held at $28^{\circ} \mathrm{C}$ for sensing. $28^{\circ} \mathrm{C}$ is sufficient to prevent polymer sensors from becoming saturated in sorbed water under nominal humidity conditions. However, because the ability of a polymer based sensor to detect analytes will be expected to fall off with increasing temperature, a balance between a sensor temperature high enough to prevent saturation in water and low enough to allow sorption of most analytes had to be found. In addition, it has been shown by other researchers that optimum sensing can be accomplished only if the environmental temperature (in this case temperature within the ENose) is lower than the temperature of the sensing surface [12]. For this reason, the temperature of the sensing chamber in the JPL ENose is controlled by a combination of thermoelectric devices and fans.

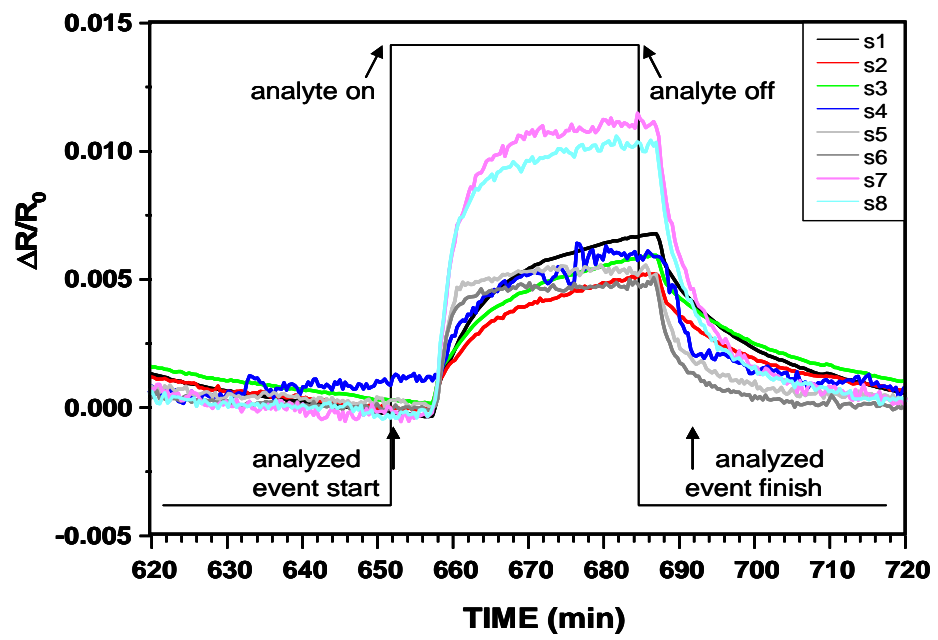

Figure 2: Sensor response to $1083 \mathrm{ppm}$ ethanol.

\section{FOLLOW PROGRESS OF CONTAMINATION EVENT}

In addition to identifying and quantifying the appearance of the analytes shown in Table 1, the function of the ENose includes following the progress of a contamination event. That is, the ENose should show both the rise in concentration of a targeted analyte as it is released into the environment, and the fall in concentration as it is cleaned up. The plots in Figures 2 and 3 show how resistance changes over time as analyte is added to then removed from the environment.

Figures 2 and 3 shows the development of resistance change data for eight sensors after analyte is let into the sensing chamber. As seen in both figures, there is a period of about 5 minutes after analyte is turned on at the vapor delivery system until the sensors show any response as change in resistance. This lag time is systematic; it is the time it takes for the concentration gradient from the vapor delivery system to reach the sensing chamber and for analyte concentration to reach its maximum in the sensing chamber. There is also a time constant for response related to each analyte and each sensor. As can be seen by comparing the rise times for sensors in Figures 2 and 3, sensors respond more rapidly to ethanol than to toluene. For these 30 minute events, sensors do not always reach equilibrium to every analyte, as can be seen for Sensors 5 and 6 in Figure 3.

After the analyte delivery is stopped, there is a period of about 10 minutes for the analyte to be flushed from the system; this period is reflected in a rapid but incomplete fall in sensor response after "analyte off." This region of the sensor response is used to track the diminishing concentration of a chemical species during a cleanup operation. The complete recovery of sensors after removal of analyte might take an additional 30 minutes after the environment is clean, as analyte desorbs from the polymer sensors; however, quantification of the sensor response in this region will show the analyte concentration to be below the lowest concentration to be

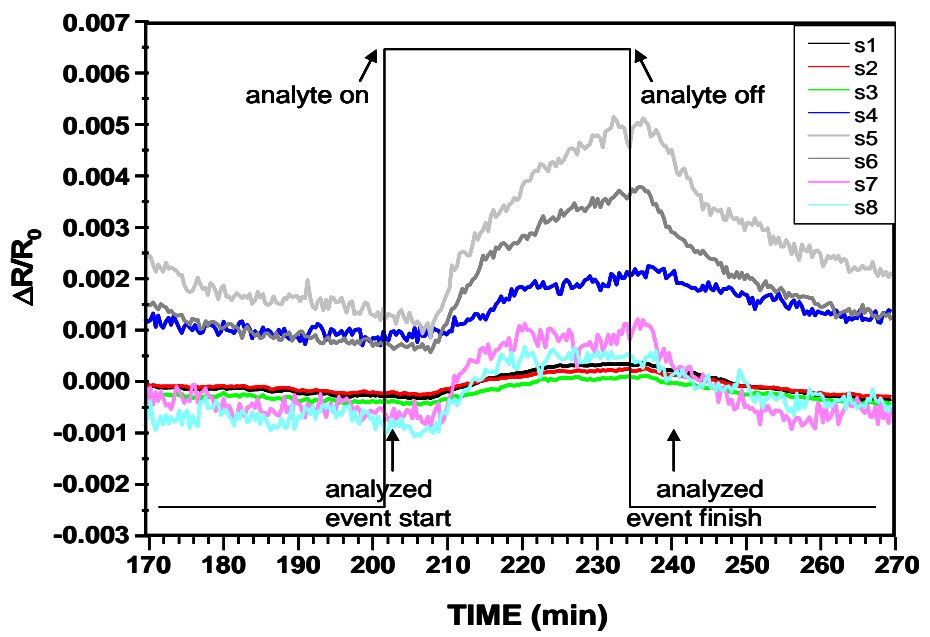

Figure 3: Sensor response to $37 \mathrm{ppm}$ toluene 
reported by the ENose.

Analysis of the onset, maximum and decline in these two examples will follow the rise and fall shown in the plots, Table 4 shows analysis for the ethanol event shown in Figure 2. In the table, the single, overall event of the appearance of ethanol lasts from 662 minutes to 693 minutes. The ethanol event is reported as four subevents; the first sub-event has a concentration of about $900 \mathrm{ppm}$, the second a concentration about $1150 \mathrm{ppm}$, the third $900 \mathrm{ppm}$, and the fourth $349 \mathrm{ppm}$, showing the rise and fall of the appearance of ethanol in the environment.

Table 4: Rise and Fall of Ethanol concentration as determined by ENose Data Analysis algorithm

\begin{tabular}{|c|c|l|c|}
\hline $\begin{array}{c}\text { Event } \\
\text { start } \\
(\mathrm{min})\end{array}$ & $\begin{array}{c}\text { Event end } \\
(\mathrm{min})\end{array}$ & Analyte ID & $\begin{array}{c}\text { Analyte } \\
\text { Conc. } \\
(\mathrm{ppm})\end{array}$ \\
\hline 652 & 663 & Ethanol & 900 \\
\hline 653 & 668 & Ethanol & 911 \\
\hline 653 & 672 & Ethanol & 1173 \\
\hline 653 & 676 & Ethanol & 1125 \\
\hline 653 & 680 & Ethanol & 1148 \\
\hline 653 & 684 & Ethanol & 1173 \\
\hline 653 & 689 & Ethanol & 900 \\
\hline 653 & 693 & Ethanol & 349 \\
\hline
\end{tabular}

\section{CONCLUSION}

In a total of 1599 exposures, the overall success rate for Tier 1 species was $89 \%$, and for Tiers $2 \& 3,80 \%$, over all humidity and pressure conditions. Weighting the success rates for number of chemical species in each category, the overall success rate for identification and quantification of delivered species in training sets was $83 \%$ over all conditions.

Success rates at nominal conditions, environmental temperature of $21-22^{\circ} \mathrm{C}$, with analyte temperature (sensing chamber temperature) at $25^{\circ} \mathrm{C}$, and 10,000 ppm water (about 40\% RH), the success rate for Tier 1 species was $93 \%$, and for Tiers 2 \& 3 was $85 \%$. The overall success rate for all species under nominal conditions was $87 \%$.

While, in general, success was improved at lower relative humidity, this was not true in all cases; nominal conditions provided the best success rates. Future work will consider whether it is possible to optimize a sensor set over all conditions, so that success rate does not vary with water content of the background air.

\section{ACKNOWLEDGMENTS}

The research reported in this paper was carried out at the Jet Propulsion Laboratory, California Institute of Technology under a contract with the National Aeronautics and Space Administration and supported by the Advanced Environmental Monitoring and Control Program, ESMD, NASA.

\section{REFERENCES}

1. M.A. Ryan, M.L. Homer, M.G. Buehler, K.S. Manatt, F. Zee, and J. Graf, "Monitoring the Air Quality in a Closed Chamber Using an Electronic Nose," Proc.

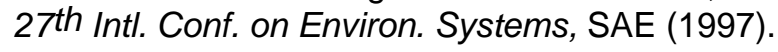

2. M.A. Ryan, M.L. Homer, M.G. Buehler, K.S. Manatt, B. Lau, D. Karmon, and S. Jackson, "Monitoring Space Shuttle Air for Selected Contaminants Using an Electronic Nose," Proc. 28th Intl. Conf. on Environ. Systems, SAE (1998).

3. M.A. Ryan, M. L. Homer, H. Zhou, K. S. Manatt, V. S. Ryan, and S. Jackson, "Operation of an Electronic Nose Aboard the Space Shuttle and Directions for Research for a Second Generation Device," Proc. 30th Intl. Conf. on Environ. Systems, SAE (2000).

4. M.A. Ryan, H. Zhou, M.G. Buehler, K.S. Manatt, V.S. Mowrey, S.P. Jackson, A.K. Kisor, A.V. Shevade, and M.L. Homer, "Monitoring Space Shuttle Air Quality Using the JPL Electronic Nose," IEEE Sensors Journal, 4, 337 (2004).

5. M.A. Ryan, A.V. Shevade, H. Zhou and M.L. Homer, "Polymer-Carbon-Composite Sensors for an Electronic Nose Air Quality Monitor," MRS Bulletin, 29, 714 (2004).

6. Spacecraft Maximum Allowable Concentrations for Selected Airborne Contaminants, vols.1 \& 2, National Academy Press, Washington DC, 1994.

7. M.A. Ryan, M.L. Homer, H. Zhou, K. Manatt, A. Manfreda, A. Kisor, A. Shevade and S.P.S. Yen; "Expanding the Analyte Set of the JPL Electronic Nose to Include Inorganic Species;" Journal of Aerospace, SAE Transactions, 2005-01-2880 (2005).

8. M.A. Ryan, M.L. Homer, H. Zhou, K. Manatt, A. Manfreda, A. Kisor, A. Shevade and S.P.S. Yen; "Expanding the Capabilities of the JPL Electronic Nose for an International Space Station Technology Demonstration", Proc. 36 ${ }^{\text {th }}$ Intl. Conf. on Environ. Systems, SAE, 2179 (2006).

9. H. Zhou, M. L. Homer, A. V. Shevade and M. A. Ryan "Nonlinear Least-Squares Based Method for Identifying and Quantifying Single and Mixed 
Contaminants in Air with an Electronic Nose;"; Sensors, 6, 1 (2006).

10. A.V. Shevade, M.A. Ryan, M.L. Homer, A.M. Manfreda, H. Zhou, K.S. Manatt, "Molecular Modeling of Polymer Composite-Analyte Interactions in Electronic Nose Sensors," Sens. \& Act. B, 93, 84 (2003).

11. A.V. Shevade, M.A. Ryan, M.L. Homer, A.M. Manfreda, $H$. Zhou and K. Manatt, "Correlating Polymer-Carbon Composite Sensor Response with Molecular Descriptors," J. Electrochem. Soc., 153, H209 (2006).

12. E.J. Severin and N.S. Lewis, "Relationship among resonant frequency changes on a coated quartz crystal microbalance, thickness change, and resistance responses of polymer-carbon black composite chemiresistors;" Anal. Chem. 72, 2008 (2000).

\section{CONTACT}

Dr. M. A. Ryan

MS 184-105; Jet Propulsion Laboratory California Institute of Technology

4800 Oak Grove Drive

Pasadena CA 91109

tel: (818) 354-8028

email: mryan@jpl.nasa.gov 